AGRARIS: Journal of Agribusiness and Rural Development Research

Vol. 3 No.2 Juli 2017

\section{Pengambilan Keputusan Petani untuk Tetap Berusahatani Cabe Jamu di Kecamatan Bluto, Kabupaten Sumenep}

https://doi.org/10.18196/agr.3251

\begin{abstract}
This research aims to determine the factors that influence farmer decision to keep his long pepper farming in Bluto District. This research was conducted in 5 villages of the long pepper production center. A samples of 86 farmers was analized by an analysis of binary logistic. The result showed that factor influencing the farmer decision to keep his long pepper farming was the experience of farming. Increasing experience of farming will upgrade farmer knowledges in minimizing failure on long pepper farming.
\end{abstract}

Keywords: binary logistic analysis, decision making, district of Bluto, long pepper.

\section{INTISARI}

Penelitian ini bertujuan untuk mengetahui faktor yang mempengaruhi keputusan petani untuk tetap berusahatani cabe jamu. Penelitian ini dilakukan di lima desa sentra produksi cabe jamu di Kecamatan Bluto, dengan jumlah sampel sebanyak 86 petani. Data dianalisis dengan metode analisis binary logistic. Hasil penelitian menunjukkan bahwa pengalaman usahatani menjadi faktor yang mempengaruhi pengambilan keputusan petani tetap berusahatani cabe jamu di Kecamatan Bluto. Peningkatan pengalaman usahatani akan meningkatkan pengetahuan petani dalam mengurangi kegagalan dalam berusahatani cabe jamu.

Kata kunci: analisis binary logistic, cabe jamu, kecamatan Bluto, pengambilan keputusan.

\section{PENDAHULUAN}

Indonesia termasuk salah satu negara yang kaya plasma nutfah tanaman obat. Tanaman obat yang potensial untuk dimanfaatkan sebagai bahan baku jamu dan obat tradisional berjumlah lebih dari 300 dari 1000 jenis tanaman obat di Indonesia (Rukmana, 2003). Pengembangan budidaya tanaman obat memiliki dampak positif bagi masyarakat yaitu meningkatkan produksi pendapatan petani, dan pelestarian sumber daya hayati (biodiversitas) dari tanaman obat itu sendiri (Djauhariya \& Rosihan, 2009). Ratarata ekspor tanaman obat Indonesia ke H ongkong setiap tahun sebesar 730 ton, disusul Singapura 528 ton, kemudian Jerman 155 ton, Taiwan, Jepang, Korea Selatan, dan M alaysia (Dinarwi, 2007).

Salah satu tanaman obat yang saat ini sedang dikembangkan adalah cabe jamu (Piper retrofactum Vahl). Buah cabejamu banyak dibutuhkan oleh industri obat herbal yaitu sekitar 5.920 ton per tahun (H erlina, 2008). Selain itu, cabe jamu menjadi salah satu komoditi ekspor tanaman obat yang cukup diminati di pasaran internasional (A rifiyanti, M elati, \& G hulamahdi, 2009). Indonesia telah mengekspor cabejamu sejak penjajahan B elanda. Kebutuhan cabejamu dunia saat ini sekitar 6 juta ton dan Indonesia baru bisa memenuhi sepertiganya (Taryono \& A gus, 2004). 
C abe jamu banyak ditemukan di Indonesia terutama di Jawa, Lampung, Sumatera, Bali, Nusa Tenggara, dan Kalimantan. Sentra produksi cabe jamu adalah Propinsi Jawa Timur dan Lampung. DinasPerkebunan Propinsi JawaTimur (2013), mencatat pada tahun 2010 luasareal cabe jamu seluas 4.211 ha dengan produksi 1.329 ton buah kering dan produktivitas sebesar $481 \mathrm{~kg} / \mathrm{ha}$. Di J awa Timur, daerah sentra produksi utamanya adalah di Madura. Areal perkebunan terbesar di semua kabupaten terutama yang terdapat di Pulau M adura yaitu di Kabupaten Sumenep (1.709 ha), Sampang (1.017 ha), Pamekasan (715 ha), dan Bangkalan (356 ha).

Permasalahan umum dalam usahatani cabejamu adalah belum banyaknya masyarakat yang membudidayakan tanaman ini secara intensif. Dengan demikian, tidak ada perencanaan produksi yang tepat yang mengakibatkan potensi produksinya tidak tercapai. Rata-rata produksi cabe jamu kering hanya sekitar 1,48 ton/ha/ tahun, padahal potensi produksi seharusnya mencapai 2,5 ton/ ha/ tahun (Djauhariya \& Rosihan, 2009). Selain itu, budidaya cabe jamu tidak didukung oleh teknik budidaya yang baik.

Kabupaten Sumenep berpeluang sebagai tempat pengembangan tanaman cabejamu ditinjau dari sumber daya dan kondisi tanah yang sangat cocok dengan pertumbuhan tanaman cabejamu. Berdasarkan data dari Dinas Kehutanan dan Perkebunan Kabupaten Sumenep (2015), Kecamatan Bluto merupakan sentra penghasil cabe jamu di Kabupaten Sumenep. Produksi cabe jamu di Kecamatan Bluto mengalami peningkatan dari tahun 2011-2015. A kan tetapi, produktivitas cabe jamu cenderung stagnan selama kurun waktu tersebut, bahkan mengalami penurunan pada tahun 2015 (Tabel 1).

\section{TABH1 UASLAHAN PFOUKS, DANPFOU KIMTASTANAMANCABEJAM TAHNZOII2015D KECANAANBUIO}

\begin{tabular}{|c|c|c|c|c|}
\hline $\mathrm{Nb}$ & Tathon & Lestadan (1-a) & $\begin{array}{l}\text { Rodks } \\
\text { (Tor) }\end{array}$ & $\begin{array}{l}\text { Rodktivites } \\
(\mathrm{Kg} / \mathrm{H})\end{array}$ \\
\hline 1 & 2011 & 568,57 & 2095,40 & 5.131 \\
\hline 2 & 2012 & $582, \pi$ & 2179,26 & $5.131,48$ \\
\hline 3 & 2013 & ๔3,83 & 2179,63 & $5.131,56$ \\
\hline 4 & 2014 & 663,83 & 2407,03 & $5.131,56$ \\
\hline \multirow[t]{2}{*}{5} & 2015 & 667,83 & 2455,17 & 4798,54 \\
\hline & Junted & $3.096,81$ & 11316,49 & 25324,14 \\
\hline
\end{tabular}

Sumber: Dinas Kehutanan dan Perkebunan Kabupaten Sumenep, 2015

Rendahnya produktivitas cabejamu di Kecamatan Bluto disebabkan oleh banyak faktor, antara lain saluran irigasi yang kurang memadai, terserangnya hama dan penyakit serta kurangnya pengetahuan petani terhadap perkembangan teknologi terutama dalam teknik budidaya cabe jamu (Zuchri, 2008). Namun pada fakta di lapang, meskipun terdapat beberapa masalah yang menyebabkan rendahnya produktivitas cabejamu pada tahun 2015, petani tetap memasukkan komoditas cabe jamu dalam usahataninya. Padahal pada waktu yang bersamaan, masyarakat Kecamatan Bluto juga menanam komoditasjagung sebagai penambah pendapatan rumah tangga dan pemenuhan kebutuhan pangan keluarga.

Komoditas jagung di Kecamatan Bluto merupakan komoditas pangan yang memiliki produksi paling tinggi di antara komoditas pangan lainnya, yaitu sebesar 5,21 ton/ ha pada tahun 2015 (BPP Kecamatan Bluto, 2015). Salah satu penyebab dari tingginya produksi tersebut adalah dengan adanya program penyuluhan dalam mendukung U PSU S PAJALE (U paya K husus Padi, Jagung, dan Kedelai) pada tahun 2015 yan gjuga diterapkan oleh BPP Kecamatan Bluto kepada petani padi, jagung, dan kedelai. Namun, pendapatan petani cabe jamu sebesar Rp. 3.817.342/ musim ( $N$ ingsih, 2012) lebih besar dibandingkan dengan pendapatan usahatani lain yang ditanam oleh masyarakat Kecamatan Bluto.

Petani sebagai manajer harus memilih komoditas untuk diusahakan (Suratiyah, 2008). Keputusan petani untuk mengusahakan komoditas tertentu dipengaruhi oleh faktor sosial ekonomi. Beberapa studi kasus menunjukkan bahwa pendapatan usahatani dan harga jual komoditas merupakan faktor yang mempengaruhi keputusan petani untuk mengusahakan komoditas tertentu (Evayanti, Rusmadi, \& Ratina, 2004); (A priliana \& Mustadjab, 2016); (Theresia, Fariyanti, \& Tinaprilla, 2016). Faktor lainnya seperti luas lahan, tingkat pendidikan, keaktifan dalam kelompok tani, cenderung tidak signifikan dalam mempengaruhi keputusan dalam studi-studi kasus tersebut.

Berbagai studi sebelumnya menunjukkan adanya perbedaan faktor yang berpengaruh dalam pengambilan keputusan petani dalam mengusahakan komoditas tertentu. $\mathrm{H}$ al ini menunjukkan perlunya studi yang bertujuan mengetahui faktor yang mempengaruhi pengambilan keputusan petani tetap berusahatani cabejamu di Kecamatan Bluto, agar diperoleh masukan dalam upaya meningkatkan areal usahatani cabejamu di Kecamatan Bluto.

\section{METODE PENELITIAN}

Lokasi penelitian di Kecamatan Bluto, Kabupaaten Sumenep. Lokasi penelitian ditentukan secara sengaja dengan pertimbangan produksi cabe jamu di Kecamatan Bluto palingtinggi dibandingkan dengan kecamatan lain di Kabupaten Sumenep. D ata yang digunakan adalah data primer yang 
diperoleh dari hasil observasi dan wawancara dengan bantuan kuesioner. Data dari hasil observasi adalah data sosial ekonomi petani, sedangkan data hasil wawancara adalah pendapatan usahatani dan faktor-faktor yang diduga berpengaruh terhadap pengambilan keputusan petani unruk tetap berusahatani cabe jamu. Responden dalam penelitian ini yaitu 43 petani cabe jamu yang memiliki tamanam berumur lima sampai tujuh tahun dan 43 petani jagungyang juga pernah atau sedang menanam cabe jamu serta aktif dalam kelompok tani di Kecamatan Bluto. Teknik pengambilan sampel menggunakan accidental sampling, dengan pertimbangan tidak ada kerangka sampel petani cabe jamu yang memiliki umur tanaman lima sampai tujuh tahun. Selanjutnya, analisis data yang digunakan adalah analisis regresi binary logistik. Secara matematis model penelitian yang digunakan sebagai berikut:

$Y=\ln \quad\left(\mathrm{P}_{\mathrm{i}} / 1 \mathrm{P}_{\mathrm{i}}\right)=\beta_{0}+\beta_{1} \mathrm{X}_{1}+\beta_{2} \mathrm{X}_{2}+\beta_{3} \mathrm{X}_{3}+\beta_{4} \mathrm{X}_{4}+\beta_{5} \mathrm{X}_{5}+\beta_{6} \mathrm{X}_{6}+\beta{ }_{7} \mathrm{D}_{7}+\beta_{8} \mathrm{D}_{8}+\mathrm{e}$

$Y$ adalah keputusan petani $\left(P_{i}=1\right.$, tetap berusahatani cabe jamu, $P_{i}=0$, tidak berusahatani cabe jamu), $X_{1}$ adalah umur (tahun), $X_{2}$ adalah tingkat pendidikan (tahun), $X_{3}$ adalah pendapatan usahatani ( $\mathrm{R} p), X_{4}$ adalah pengalaman usahatani (tahun), $\mathrm{X}_{5}$ adalah luas lahan ( $\left.\mathrm{Ha}\right), \mathrm{X}_{6}$ adalah frekuensi kontak dengan petani lain (kali/ bulan), $X_{7}$ adalah tingkat kesulitan budidaya ( 1 = mudah, 0 = sulit), $X_{8}$ adalah keikutsertaan kelompok tani ( $1=$ ikut serta, $0=$ tidak ikut serta).

\section{HASIL DAN PEMBAHASAN}

\section{KARAKTERISTIK RESPONDEN PETANI DI KECAMATAN BLUTO}

Tanaman cabe jamu merupakan tanaman yang saat ini banyak diusahakan oleh masyarakat Kecamatan Bluto. Kondisi tanah yang sangat cocok menjadi salah satu pendukung petani untuk tetap mengusahakan usahatani cabejamu. M engusahakan cabe jamu sudah menjadi hobi dari kebanyakan petani di Kecamatan Bluto. Selain pendapatan yang dihasilkan tinggi, cabe jamu juga merupakan tanaman tahunan yang tahan terhadap serangan penyakit.

Selain menanam cabejamu, mayoritas masyarakat Bluto juga menanam jagung untuk memenuhi kebutuhan pangan dan juga dijual untuk mendapatkan tambahan pendapatan. Jagung merupakan komoditas pangan dengan produksi tertinggi di Kecamatan Bluto (BPP Kecamatan Bluto, 2016). Tingginya produksi tersebut juga didukung oleh adanya program U PSU S PAJALE yang diadakan oleh BPP Kecamatan Bluto. Masyarakat Kecamatan Bluto tidak hanya menanam cabe jamu, melainkan juga menanam jagung karena kondisi tanah yang cocok ditanami oleh kedua komoditas tersebut.
Menurut (Theresia, 2016), ciri spesifik dari seseorang seperti umur, tingkat pendidikan, pengalaman usahatani, dan luas lahan berpengaruh terhadap keterampilan petani dalam mengelola usahatani. U mur mayoritas petani di Kecamatan Bluto termasuk pada kategori umur produktif, yaitu sebanyak 99\% petani berumur. $\mathrm{Hal}$ tersebut menunjukkan bahwa umur yang produktif akan lebih cepat menerima inovasi dan informasi untuk diaplikasikan pada usahataninya.

Tingkat pendidikan formal sebagian besar petani adalah tingkat pendidikan SMA/ sederajat, yaitu sebanyak 53,5\% petani. Petani yang mempunyai tingkat pendidikan SM P/ sederajat sebanyak $24,4 \%$, SD/ sederajat sebanyak $16,3 \%$, Diploma sebanyak 2,3\%, dan Sarjana sebanyak 2,3\%. Persentase terbesar adalah tingkat pendidikan SMA/ sederajat. Tingkat pendidikan ini sudah cukup, karena sesungguhnya petani sudah memiliki dasar dan pemikiran kearah pertanian yang berkelanjutan, hanya saja masih harus lebih diasah untuk menimbulkan kesadaran tersebut (Kurniati, 2005). Sedangkan tingkat pendidikan di atas SD akan lebih mudah mengikuti pembinaan yang dilakukan dan mengolah informasi yang diterima dengan cepat.

Sebanyak $46,5 \%$ petani di Kecamatan Bluto memiliki lahan antara 0, 25-0,50 ha, dan sebanyak 2,3\% petani yang mempunyai luas lahan $>1 \mathrm{Ha}$. Pendapatan usahatani yang diperoleh petani di Kecamatan Bluto diperoleh dari hasil usahatani tembakau, kacang hijau, jagung, dan cabe jamu. $\mathrm{N}$ amun ada juga yang diperoleh dari hasil usahatani jagung dan cabe jamu saja. Sebanyak 20 orang petani cabe jamu dan 29 orang petani jagung di Kecamatan Bluto mempunyai pendapatan sebesar R p 1.000.000 Rp 10.000.000. Petani yang berpendapatan kurang dari Rp1.000.000 ditemukan sebanyak $1 \%$ petani cabe jamu. Sedangkan petani yang memiliki pendapatan Rp. 10.100.000 - Rp 20.000.000 ditemukan sebanyak 18 orang petani cabe jamu dan 33\% petani jagung. Pendapatan lebih dari Rp 20.000.000 diperoleh oleh petani cabe jamu dan jagung sebanyak $6 \%$. Perbedaan pendapatan tersebut disebabkan oleh hasil produksi yang berbeda-berbeda di antara petani satu dan petani lainnya di Kecamatan Bluto.

Pengalaman usahatani setiap orang berbeda-beda, begitu pun pengalaman usahatani petani cabe jamu dan jagung di Kecamatan Bluto. M ayoritas petani $(67,4 \%)$ di Kecamatan Bluto melakukan usahatani cabe jamu dan jagung dalam jangka waktu kurang dari 10 tahun, yaitu sebanyak 43 orang petani cabe jamu dan 15 orang petani jagung. Sebanyak 27 orang petani cabejamu dan jagungyang melakukan usahatani dalam jangka waktu 10-30 tahun. Sedangkan yang lebih dari 30 tahun ditemukan sebanyak 1,2\% petani cabe jamu dan 
jagung. Perbedaan lamanya berusahatani tersebut dapat dijadikan bahan pertimbangan agar tidak melakukan kesal ahan yang sama sehingga dapat melakukan hal-hal yang baik untuk waktu-waktu berikutnya (H asyim, 2006).

Frekuensi kontak dengan petani lain sebanyak kurang dari 10 kali/ bulan dilakukan oleh $64 \%$ petani. U sahatani jagung tidak membutuhkan pengawasan setiap hari, sehingga frekuensi kontak dengan petani lain kurang dari 10 kali/ bulan didominasi oleh petani jagung. Sedangkan $34 \%$ petani melakukan kontak dengan petani lain dengan frekuensi 1020 kali/ bulan yang didominasi oleh petani cabejamu dengan jumlah 24 orang dan 5 orang petani jagung. D apat dikatakan bahwa petani cabe jamu lebih sering berinteraksi dengan petani lain karena petani cabe jamu setiap hari mengontrol tanaman di tegalan dan bertemu dengan petani lain selain di rumah petani masing-masing.

M ayoritas petani $(72 \%)$ ikut serta dalam kegiatan kelompok tani dan sebesar $28 \%$ tidak ikut serta dalam kegiatan kelompok tani. D alam kegiatan kelompok tersebut hadir pula PPL yang bertindak sebagai narasumber untuk memberikan penjelasan mengenai budidaya tanaman. Dalam kegiatan kelompok, kadangkala terjadi diskusi dengan petani lain yang pernah mengalami persoalan dalam usahatani. Dengan demikian keikutsertaan petani dalam kelompok tani memberikan manfaat memberikan informasi terkait dengan permasalahan pertanian atau informasi mengenai teknologi baru di bidang pertanian (Watemin \& Sulistyani, 2015).

Tingkat kerumitan budidaya cabe jamu dikategorikan mudah. Sebanyak $86 \%$ petani menyatakan bahwa tingkat kerumitan budidaya cabe jamu dikategorikan mudah. $M$ ayoritas petani di Kecamatan Bluto tidak mengalami kesulitan untuk melakukan usahatani dan menerima informasi yang berkaitan dengan cabe jamu dan jagung.

\section{FAKTOR-FAKTOR YANG M EM PENGARUHI KEPUTUSAN PETANI UNTUK TETAP BERUSAHATANI CABE J AMU}

Keputusan petani untuk tetap berusahatani cabe jamu di Kecamatan Bluto dipengaruhi ol eh banyak faktor. Faktor yang diduga mempengaruhi keputusan petani untuk tetap berusahatani cabe jamu dalam penelitian ini adalah umur, tingkat pendidikan, pendapatan usahatani, pengalaman usahatani, luas lahan, frekuensi kontak dengan petani lain, tingkat kesulitan budidaya, dan keikutsertaan kel ompok tani. $\mathrm{H}$ asil analisis pengaruh faktor variabel tersebut terhadap pengambilan keputusan petani untuk tetap berusahatani cabe jamu dengan menggunakan regresi binary logistic dapat dilihat pada Tabel 2.

\section{TAM田2 HASLANALSSFECPE BNAPYLOSTICFAKICRYANG MEMPENGAR H RENAMELANKEPUIUSNFEIAN UNIUKIEIAP BERSAHAVAN CABEJAMUD KECAMATNBUTOTAHNZOOD}

\begin{tabular}{|c|c|c|c|c|}
\hline Verizad & Q & VAtc & Sc & $\mathrm{Ep}(\mathrm{Q})$ \\
\hline Uher $(X)$ & .049 & .315 & $.5 / 5$ & 1050 \\
\hline TingetPenddkan(x) & -.410 & 2227 & .136 & .664 \\
\hline Penceptan Usathatai (\rangle$\left._{3}\right)$ &.$\infty$ & $.24 \varepsilon$ & ๔ & 100 \\
\hline PengdananUsatatai (\rangle$\left._{4}\right)$ & -2066 & $5.0 T=$ & $\left..024^{*}\right)$ & .126 \\
\hline Leslaten $\left(>_{5}\right)$ & 7.385 & 2536 & .110 & $1 凹 \mathbb{E}$ \\
\hline Frekens KortekdengenPetai lain (\rangle$\left._{6}\right)$ & .155 & 1304 & .256 & 1171 \\
\hline TingktKerunitan Bddaja(X) & -1868 &.$\infty 0$ & .998 &.$\infty$ \\
\hline KéktsetankAonpokTari (X) & -20288 &.$\infty$ & .998 & .00 \\
\hline Konstata & 49.972 &.$\infty$ & .997 & 5.04572 \\
\hline \multicolumn{5}{|l|}{ Chi Square Htung = 98.642} \\
\hline \multicolumn{5}{|l|}{ Negelkerge R Square $=.910$} \\
\hline Overall Percentage $=942$ & & & & \\
\hline
\end{tabular}

Sumber: Data Primer Diolah, 2017 Keterangan :*) Nyata pada á $=0.05$

Variabel independen umur, tingkat pendidikan, pendapatan usahatani, pengalaman berusahatani, frekuensi kontak dengan petani lain, luas lahan, tingkat kesulitan budidaya cabe jamu, dan keikutsertaan dalam kelompok tani mampu mempengaruhi variabel dependen keputusan petani untuk tetap berusahatani cabejamu di Kecamatan Bluto. Keputusan petani untuk tetap berusahatani cabe jamu di Kecamatan Bluto sebesar $91 \%$ mampu dijelaskan oleh faktor umur, tingkat pendidikan, pendapatan usahatani, pengalaman usahatani, frekuensi kontak dengan petani lain, luas lahan, tingkat kesulitan budidaya, dan keikutsertaan kelompok tani. Sedangkan sisanya, sebesar $9 \%$ dijelaskan oleh variabel lain di luar model. Tabel 2. menjelaskan bahwa nilai overall percentage sebesar 94,2 yang menunjukkan bahwa model regresi binary logistic yang digunakan sudah baik karena mampu menduga dengan benar sebesar $94,2 \%$.

Pengaruh secara parsial atau individu dari variabel independen terhadap variabel dependen dalam penelitian ini dapat dilihat dari hasil uji wald. Dari tabel 2. tersebut dapat dilihat bahwa umur, tingkat pendidikan, pendapatan usahatani, frekuensi kontak dengan petani lain, luas lahan, tingkat kesulitan budidaya, dan keikutsertaan kelompok tani tidak berpengaruh secara signifikan, sedangkan pengalaman usahatani berpengaruh signifikan terhadap pengambilan keputusan petani untuk tetap berusahatani cabe jamu.

U mur. Berdasarkan analisis logistik secara parsial, diketahui bahwa variabel umur $\left(X_{1}\right)$ tidak berpengaruh nyata terhadap pengambilan keputusan petani untuk tetap berusahatani cabe jamu di Kecamatan Bluto. Berbagai kelompok usia petani, baik muda maupun tua tetap memiliki 
kemampuan yang sama dalam mengadopsi inovasi dan menyerap informasi tentang usahatani cabe jamu. Bahkan dalam hal tanggung jawab, semakin tua usia tenaga kerja tidak akan berpengaruh karena justru semakin berpengalaman (Suratiyah, 2008). Hal ini sejalan dengan penelitian (Apriliana \& M ustadjab, 2016) bahwa variabel umur tidak berpengaruh terhadap pengambilan keputusan petani dalam menggunakan benih jagung hibrida di Kabupaten $\mathrm{M}$ alang. Tingkat Pendidikan, Petani yang berpendidikan tinggi adalah relatif lebih cepat dal am melaksanakan adopsi inovasi. B egitu pula sebaliknya petani yang berpendidikan rendah akan sedikit mengalami kesulitan untuk melaksanakan adopsi inovasi dengan cepat (Soekartawi, 1988). Namun secara statistik variabel tingkat pendidikan $\left(X_{2}\right)$ tidak berpengaruh nyata terhadap pengambilan keputusan petani untuk tetap berusahatani cabe jamu. Berusahatani cabe jamu tidak memerlukan tingkat pendidikan yang tinggi, karena petani mendapatkan banyak ilmu tentang berusahatani cabe jamu di luar pendidikan formal, yaitu dengan mengamati usahatani petani lain, melakukan inovasi sendiri secara terus-menerus dan belajar kepada sesama petani. H asil analisis ini sejalan dengan penelitian (Evayanti, Rusmadi, \& N ita 2004) bahwa dalam pendidikan formal petani tidak diajari tentang tata cara menanam $\mathrm{N}$ enas dengan baik dan benar.

Pendapatan usahatani. Variabel pendapatan usahatani tidak berpengaruh nyata terhadap pengambilan keputusan petani untuk tetap berusahatani cabe jamu. Petani di Kecamatan Bluto menganggap bahwa tinggi atau rendah pendapatan usahatani yang dimiliki petani tetap melakukan usahatani cabe jamu. Pemilihan petani atas hasil produksi berdasarkan pendapatan yang petani harapkan dan penjualan produksi yang diusahakan (Theresia, 2016). Sebelum memilih dan mengusahakan suatu komoditas, petani mempertimbangkan besar kecilnya pendapatan yang diperoleh dari pengusahaan komoditi tersebut. Semakin tinggi tingkat pendapatan maka semakin cepat kemampuannya menghadapi inovasi (H anafie, 2010).

Komoditas cabe jamu di Kecamatan Bluto merupakan komoditas yang memiliki harga jual paling tinggi di antara komoditas lainnya yaitu sebesar R p. $55.000 / \mathrm{kg}$. H arga cabe jamu yang tinggi ini menjadi daya tarik petani. O leh karena itu, pendapatan usahatani cabe jamu tidak berpengaruh terhadap pengambilan keputusan petani untuk tetap berusahatani cabe jamu. $\mathrm{H}$ al tersebut sejalan dengan penelitian (Santika, Arik, \& Titin, 2014) yang menemukan variabel pendapatan tidak berpengaruh nyata terhadap pengambilan keputusan petani berusahatani kacang panjang di Kabupaten Jember.
Pengalaman B erusahatani. Variabel pengalaman berusahatani $\left(\mathrm{X}_{4}\right)$ berpengaruh nyata terhadap pengambilan keputusan petani untuk tetap berusahatani cabe jamu di Kecamatan Bluto. Sejalan dengan penelitian (Santika, A rik, $\&$ Titin, 2014), yang menyatakan bahwa variabel pengalaman berusahatani merupakan faktor yang berpengaruh terhadap keputusan petani berusahatani benih kacang panjang di D esa Angdongsari Kabupaten Jember. Variabel pengalaman berusahatani ini, memilik nilai exp (?) sebesar 0,126 yang artinya setiap peningkatan pengalaman usahatani meningkatkan peluang pengambilan keputusan petani untuk tetap berusahatani cabe jamu. Semakin lama petani berusahatani cabe jamu maka semakin terampil dan cepat dalam menangani risiko usahataninya. Karena petani yang mempunyai pengalaman lebih Iama cenderung lebih cepat mengambil keputusan dengan keterampilan, kemampuan, inovasi, dan permasalahan usahatani yang pernah dialami tidak diulangi lagi (Becot, Jane, \& Ernesto, 2014).

Luas Lahan. Variabel luas lahan $\left(X_{5}\right)$ tidak berpengaruh nyata terhadap pengambilan keputusan petani untuk tetap berusahatani cabe jamu di Kecamatan Bluto. Petani tetap menanam cabe jamu meskipun pada lahan yang sempit. Produksi cabe jamu yang tinggi dapat dilakukan dengan pemeliharaan dengan baik. Selain itu cabe jamu juga dapat ditanam dipekarangan rumah yang petani miliki. Suatu usahatani yang dijalankan dengan tertib dan administrasi yang baik serta teknologi yang tepat, tetap tercapai efisien meskipun dilakukan pada lahan yang sempit (Daniel, 2004). Tidak berpengaruhnya luas lahan terhadap pengambilan keputusan petani untuk tetap berusahatani cabe jamu, sejalan dengan penelitian (A deogun, Ajana, Ayinla, \& Yahere, 2008), bahwa luas lahan tidak berpengaruh terhadap penggunaan benih lele hibrida di Nigeria.

Frekuensi Kontak dengan Petani Lain. Variabel frekuensi kontak dengan petani lain tidak berpengaruh nyata terhadap pengambilan keputusan petani untuk tetap berusahatani cabe jamu. $\mathrm{H}$ al tersebut terjadi, karena petani lain belum tentu membahas tentang cabejamu dal am setiap berinteraksi. Terkadang petani lain lebih banyak membahas usahatani lain dan permasalahan sosial ekonomi di luar pertanian. O leh karena itu, frekuensi kontak dengan petani lain tidak berpengaruh terhadap pengambilan keputusan untuk tetap berusahatani cabejamu. $\mathrm{H}$ asil penelitian tersebut bertolak belakang dengan hasil penelitian (A deogun, Ajana, Ayinla, \& Yahere, 2008), yang menyatakan bahwa variabel frekuensi kontak dengan petani berpengaruh nyata terhadap pengambilan keputusan petani dalam menggunakan benih lele hibrida di N igeria. 
Tingkat Kesulitan B udidaya. Variabel tingkat kesulitan budidaya cabe jamu $\left(D_{7}\right)$ secara statistik tidak berpengaruh nyata terhadap pengambilan keputusan petani untuk tetap berusahatani cabe jamu. Pelaksanaan usahatani dengan mudah dapat dimengerti oleh petani. Semakin mudah dipahami dan dimengerti petani maka semakin baik dalam meningkatkan produktivitas pertaniannya (C epriadi \& Roza, 2012).

Cabejamu merupakan tanaman yangtidak manja, mudah dijalani, bisa ditinggalkan dan tahan terhadap penyakit sehingga dalam memelihara cabejamu hanya membutuhkan pengawasan saja. D alam menjalankan usahatani cabejamu, petani menganggap sebagai pengisi waktu luang dan hobi yang sedang dijalani, sehingga tingkat kesulitan dalam membudidayakan cabe jamu tidak berpengaruh terhadap pengambilan keputusan petani untuk tetap berusahatani cabe jamu. $\mathrm{H}$ asil penelitian ini bertolak belakang dengan hasil penelitian (Rachman, Jani, \& Sudarko, 2014), yang menyatakan bahwa tingkat kemudahan budidaya Kubis menjadi faktor penentu petani berusahatani Kubis di Kabupaten Bondowoso.

Keikutsertaan dalam Kelompok Tani. Variabel keikutsertaan dalam kelompok tani $\left(D_{8}\right)$ secara statistik tidak berpengaruh nyata terhadap pengambilan keputusan petani untuk tetap berusahatani cabe jamu. $\mathrm{H}$ al tersebut sejalan dengan penelitian (A priliana \& M ustadjab, 2016) mengenai pengambilan keputusan petani terhadap penggunaan benih jagung hibrida di Kabupaten Malang. Penelitian tersebut menyatakan bahwa keikutsertaan petani dalam kelompok tani juga tidak berpengaruh terhadap penggunaan benih jagung hibrida di K abupaten M alang. Berdasarkan fakta di lapang, untuk memperoleh informasi tentang cabejamu tidak harus aktif dalam kelompok tani tetapi belajar pada petani lain dan mengamati petani lain. Selain itu, mayoritas kelompok tani di Kecamatan Bluto tidak membahas tentang permasalahan yang terjadi pada usahatani cabe jamu melainkan lebih fokus pada pertanian pangan.

\section{KESIMPULAN}

Faktor yang berpengaruh terhadap pengambilan keputusan petani tetap berusahatani cabejamu di Kecamatan Bluto adalah pengalaman berusahatani petani. Petani diharapkan tetap melakukan usahatani cabe jamu untuk meningkatkan pengalaman petani dalam berusahatani cabe jamu. Selain itu, stakeholder di Kecamatan Bluto perlu memberikan pelatihan dalam upaya peningkatan produksi cabejamu.

\section{DAFTAR PUSTAKA}

Adeogun, O.A., Ajana, Ayinla, \& Yarhere. (2008). Application of Logit Model in Adoption Decision: A Study of Hybrid Clarias in Lagos State, Nigeria. American-Eurasian J. Agric. And Environ Sci, 4(4): 468-472.

Apriliana, M.A., \& Mustadjab, M.M. (2016). Analisis Faktor-Faktor yang Mempengaruhi Pengambilan Keputusan Petani dalam Menggunakan Benih Hibrida pada Usahatani Jagung (Studi Kasus di Desa Patokpicis, Kecamatan Wajak, Kabupaten Malang). Jurnal Habitat, 27(1): 7-13.

Arifiyanti, I. N., M elati, M., \& Ghulamahdi, M. (2009). Studi Pertumbuhan Cabe Jawa Panjat (Piper retrofractum Vahl) di Pembibitan dari Tiga Sentra Produksi. Prosiding Seminar Departemen Agronomi dan Hortikultura, Departemen Agronomi dan Holtikultura Fakultas Pertanian Institut Pertanian Bogor.

Badan Penyuluh Pertanian Kecamatan Bluto. (2015). Data Produktivitas Tanaman Pangan BBP Bluto.

Becot, David, SC., Jane, M.K., \& Ernesto, M. (2014). Measuring the Cost of Production and Pricing on Diversified Farms: Juggling Decisions Amidst Uncertainties. Journal of the ASFM RA, 2 (1): 174-191.

Cepriadi, \& Roza, Y. (2012). Persepsi Petani terhadap Usahatani Lahan Pekarangan (Studi Kasus Usahatani Lahan Pekarangan di Kecamatan Kerinci Kabupaten Pelalawan). Indonesian Journal of Agricultural Economics (IJAE), 3(2): 177-194.

Daniel, M. (2004). Pengantar Ekonomi Pertanian. Jakarta: PT Bumi Aksara. Dinarwi. (2007). Meningkatkan Mutu Cabe Jamu Lamongan Melalui Perbaikan Teknologi Pengeringan. Cakrawala, 1(1): 87 - 96.

Dinas Kehutanan dan Perkebunan Kabupaten Sumenep. (2015). Luas Lahan, Produksi, dan Produktivitas Cabe Jamu Tahun 2011-2015 di Kecamatan Bluto.

Dinas Perkebunan Propinsi Jawa Timur. (2013). Perkebunan Rakyat di Jawa Timur Tahun 2010. http://www.disbun.jatimprov.go.id/publikasi. Diakses tanggal 15 September 2016.

Djauhariya, E., \& Rosihan, R. (2009). Status Teknologi Tanaman Cabe Jamu (Piper retrofractum Vahl). Balai Penelitian Tanaman Obat dan Aromatik, 2(1): 75-90.

Evayanti, N., Rusmadi, \& Rita, R. (2004). Faktor-Faktor Sosial Ekonomi yang Mempengaruhi Keputusan Petani Mengusahakan Usahatani Nenas di Desa Sungai Merdeka. EPP, 1(1): 17-21.

Hanafie, R. (2010). Pengantar Ekonomi Pertanian. Yogyakarta: C.V Andi Offset.

Hasyim, H. (2006). Analisis Hubungan Karakteristik Petani Kopi terhadap Pendapatan (Studi Kasus: Desa Dolok Saribu Kecamatan Paguruan Kabupaten Tapanuli Utara). Jurnal Komunikasi Penelitian, 2(1): 2227.

Herlina. (2008). Tanaman Herbal di Indonesia. Seminar Terbuka Tanaman Herbal di Indonesia, Herbal Media Center Malang.

Kurniati, E. (2005). Faktor Penentu Keputusan Tanam dalam M ewujudkan Pertanian Berkelanjutan. Jurnal Teknologi Pertanian. 6(1).17-28

Ningsih, K. (2012). Analisis Titik Impas Cabe Jamu (Piper rectrofractum Vahl). 3(2).1-6.

Rachman, N., Jani, J., \& Sudarko. (2014). Faktor-Faktor yang Mendasari Pengambilan Keputusan Petani Berusahatani Kubis dan Strategi Pengembangan Usahatani Kubis. Berkala IImiah Pertanian, 1(2): 111.

Rukmana, R. (2003). Cabai Jawa Potensi dan Khasiatnya bagi Kesehatan. Yogyakarta: Kanisius.

Santika, N., Arik, S., \& Titin, A. (2014). Analisis Faktor-Faktor yang Mempengaruhi Pengambilan Keputusan Petani untuk Melakukan Usahatani Benih Kacang Panjang di Desa Andongsari Kecamatan Ambulu Kabupaten Jember (Studi Kasus Kemitraan Usahatani Benih Kacang Panjang dengan PT. Benih Citra Asia, PT. Bisi, dan PT. M atahari). 
Berkala Ilmiah Pertanian, 10(10): 1-7.

Santoso, S. (2014). Statistik Parametrik. Jakarta: PT Elek M edia Kompotindo Sarker, MA., Itohara., \& Hoque. (2009). Determinants of Adoption Decision: The Case of Organic Farming (OF) in Bangladesh. Extension Farming Systems Journal, 5(2): 39-46.

Shinta, A. (2011). Ilmu Usaha Tani. Malang: UB Press.

Soekartawi. (1988). Prinsip Dasar Komunikasi Pertanian. Jakarta: UI-Press. Soerjandono, N.B. (2008). Teknik Produksi Jagung Anjuran di Lokasi Prima Tani Kabupaten Sumenep. Buletin Teknik Pertanian, 13(1): 27-29.

Sugiarti, T., \& M ardiyah, H. (2009). Persepsi Petani M adura dalam Menolak Komoditas Jagung Varietas Baru. Embryo, 6(1): 35-46.

Sugiarto, Tedy, H., Brastoro, Rachmat, S., \& Said, K. (2005). Ekonomi Mikro Sebuah Kajian Komprehensif. Jakarta: PT Gramedia Pustaka Utama.

Suratiyah, K. (2008). IImu Usahatani. Jakarta: Penebar Swadaya.

Theresia, V., Fariyanti, A., \& Tinaprilla, N. (2016). Pengambilan Keputusan Petani Terhadap Penggunaan Benih Bawang Merah Lokal dan Impor di Kabupaten Cirebon, Jawa Barat. AGRARIS: Journal of Agribusiness and Rural Development Research, 2(1): 50-60.

Taryono, \& Agus, R. (2004). Cabe Jawa. Jakarta: Penebar Swadaya.

Watemin \& Sulistyani, B. (2015). Pemberdayaan Petani M elalui Penguatan Modal Kelembagaan Petani di Kawasan Agropolitan Kecamatan Belik Kabupaten Pemalang. Agriekonomika, 4 (1): 50-58.

Zuchri, A. (2008). Habitus dan Pencirian Tnaman Cabe Jamu (Piper retrofractum Vahl) Spesifik Madura. Agrovigor, 1(1): 39-44. 